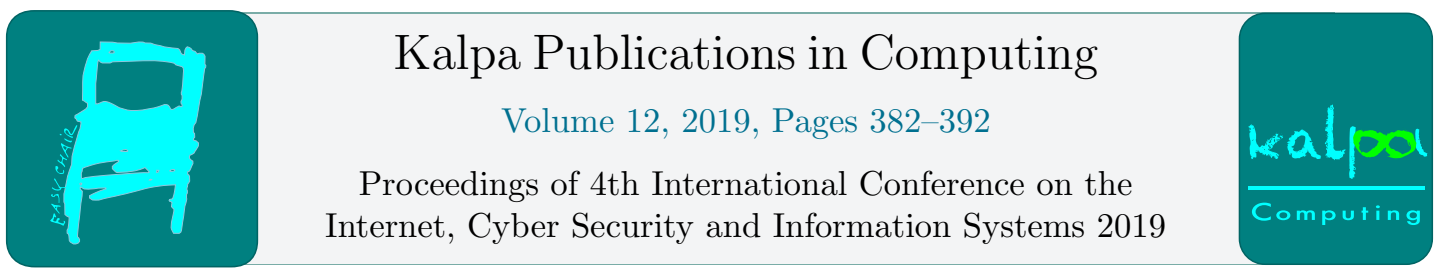

\title{
Attitudes of Belgian Companies towards Outsourcing Microwork to Africa
}

\author{
Jean-Paul Van Belle ${ }^{1}$, Karijn Bonne ${ }^{2}$, Ilse Cocquyt ${ }^{3}$ and Malcolm Garbutt ${ }^{4}$ \\ ${ }^{1,4}$ University of Cape Town, Cape Town, South Africa \\ ${ }^{2,3}$ Artevelde Hogeschool, Gent, Belgium \\ 1 jean-paul.vanbelle@uct.ac.za
}

\begin{abstract}
.
This research investigates the attitude of Belgian companies to outsource microwork to Africa. Microwork has the potential of alleviating high youth unemployment in Africa and simultaneously improving African digital economies. The purpose of this research is to find out whether overseas companies are already making use of micro job outsourcing, which platforms are used for this, which jobs are being outsourced and whether there is interest in those companies that still do not use micro work. The research also discusses the barriers that prevent companies to outsource microwork to Africa. 196 companies in Flanders (Belgium) were surveyed using a questionnaire. Five recommendations are presented, based on the perceived barriers and issues, to entice them to start or increase outsourcing micro-work to Africa.
\end{abstract}

Keywords: Microwork, Impact sourcing, Africa, ICT4D, North-South platform work.

\section{Introduction}

Outsourcing of microwork to Africa can benefit both Africa and the outsourcing country. It can alleviate rampant unemployment in Africa (Onkokame, Schoentgen \& Gillwald, 2018). And, although there might be a corresponding impact on the outsourcing country's labour market, companies would increase their global competitive advantage by achieving efficiencies and cost benefits, leading to economic growth (Mtsweni, \& Burge, 2014).

Given that the potential benefits for the countries receiving outsourcing work have already been researched, this research takes the viewpoint of the outsourcing company, in particular the outsourcing of microwork from the largest region in Belgium, namely the Flemish community. There are a number of negative perceptions among European companies about outsourcing work to developing countries, and in particular to the African continent (Roomaney, Van Belle, \& Tsibolane, 2018). By contrast, many African governments are currently trying to attract work via electronic labour-broking platforms as part of their 4IR (Fourth Industrial Revolution) strategy to alleviate local unemployment (Van Belle \& Mudavanhu, 2018). This research set out to investigate the outsourcing provider perspective and use 
these to propose tangible strategies to encourage non-African organisations to outsource micro-work to Africa-based workers. To this end, the following research question was posed: "How can Flemish companies be encouraged to outsource tasks to African micro-workers?" To answer the main research question, three sub-questions are posed:

Are there any Flemish companies with microwork outsourcing experience?

What are the barriers for companies intending to outsource to Africa?

What attitude do Flemish companies have towards outsourcing microwork to African workers?

With the aim of developing a strategy to promote outsourcing microwork from Flemish companies to the African continent, this report proceeds as follows. In the next section on overview of microwork is provided in relation to Africa and Belgium followed by research conducted in 198 Flemish companies. The findings are presented and discussed in the fourth section and recommendations provided in section 5 .

\section{Definition and Context of Microwork}

Microwork is one or more relatively simple tasks that can be performed in seconds or minutes which combine into larger tasks to form projects (Roomaney, Van Belle, \& Tsibolane, 2018). These microwork tasks are typically offered online and require only basic skills. The tasks are humanly simplistic but complex for computer programs making it more efficient when companies outsource the tasks to people for a low fee (Meyers, Minic, Raftree, \& Hurst, 2017).

Examples of microwork that can be outsourced are organizing data; typing services; transcriptions (speech recognition); retyping data; removing duplicate data; analysing images and image tagging (Onkokame, Schoentgen \& Gillwald, 2018). Microwork is similar to online freelancing where companies contract professional services from workers. Since online freelancing typically requires specific skills and experience most online freelancers have a higher education degree. Online freelancing jobs also require more time to implement and consequently freelancers earn more than micro-workers. Some examples of online freelancing are graphic design, website development and technical writing (Bukht \& Heeks, 2017).

Whereas an algorithm can measure the quality of the microwork, freelancer work requires supervisors (Kuek et al., 2015). Consequently, notable differences between microwork and online freelancing work are the size and complexity of the work and the amount of compensation. However, the similarities between microwork and online freelancing result in them being often confused with each other. This is mainly seen in tasks of moderate complexity which could be considered either as microwork or online freelancing (Kuek et al., 2015)

\subsection{Benefits and constraints}

Microwork outsourcing provides opportunities and limitations for companies and micro workers. Global outsourcing of microwork provides access to a large international market and offers microworkers opportunities to perform tasks for international companies (Van Belle \& Mudavanhu, 2018). Since the launch of the of Amazon Mechanical Turk microwork platform in 2005, the microwork market has seen increasing numbers of platforms offering microwork such as Samasource and Jana (Boyd, 2014). With the increase in the use of microwork there has been an increase in "impact sourcing" or "socially responsible outsourcing" whereby companies seek to offer work to people in disadvantaged situations. Presumably, a continent with high unemployment rates, such as Africa, could benefit significantly from microwork. At the same time, micro-workers can improve their skills and thus positively impacting unemployment rates (Onkokame, Schoentgen \& Gillwald, 2018).

\section{Impact of microwork on businesses.}


Microwork outsourcing holds both advantages and disadvantages for businesses (Van Belle \& Mudavanhu, 2018).

Benefits.

Increased productivity: A primary advantage for businesses is the potential to increase the productivity of the company. A greater workforce across multiple time zones means that tasks can be completed quicker than local workers alone (May, 2013; Amazon Mechanical Turk, n.d.).

Cost reduction: The second most important benefit is cost savings as microwork wages are significantly lower than an employed person. Micro-workers are also only paid for work done, unlike full-time employees who also have non-value adding tasks.

Focus on core business: Microwork allows simple, but time-consuming tasks to be outsourced which frees up employees to focus on the core business (Van Belle \& Mudavanhu, 2018).

\section{Constraints.}

Legislation: One disadvantage for the companies is the paucity of regulations for outsourced microwork. Outsourcing companies may also not be aware of local regulations making the company vulnerable to legal risks.

Poor payment platforms: Poor payment processes of microwork platforms and high transaction costs negatively influences micro work in international countries both from the demand and supply side (The World Bank, 2013).

Intellectual property: Outsourcing many small tasks to a large group of micro-workers increases the risk of sensitive business information and intellectual property being leaked. Even with nondisclosure agreements in place, there are risks of data leaks.

\section{Impact of microwork on workers.}

Similarly, microwork outsourcing holds both advantages and disadvantages for micro-workers (Graham, Hjorth \& Lehdonvirta, 2017).

Some benefits are:

Skills development: Microwork can provide workers with the opportunity to develop skills that may help them with future employment. These skills include specific micro-job skills while building professionalism, efficiency, proficiency, and punctuality (McManus, 2016).

Flexible income: Microwork allows for flexible income earning by allowing workers to decide how many hours they are prepared to work (Van Belle \& Mudavanhu, 2018).

Flexible working conditions: Microwork also allows the flexibility of operating conditions. For instance, micro-workers can reduce transportation costs by working from home (Jabu Mtsweni, n.d.; Boyd, 2014).

\section{Constraints are:}

De-humanisation of work: A disadvantage of microwork is its dull and repetitive nature resembling assembly-line work. Together with lack of contact between employers and employees, this can lead to de-humanisation of work and mental exhaustion (The World Bank, 2013).

Inadequate infrastructure: In more impoverished communities, micro-workers may not have optimum equipment for the tasks while low-quality infrastructure such as electricity supply or Internet connectivity can lead to inefficient working conditions (The World Bank, 2013).

Wage policy: Without adequate legislative protection, micro-workers may end up working below a living wage especially as they enjoy neither employee benefits nor job security (The World Bank, 2013). 
Lack of soft skills: A significant impact on the employment of African workers by micro foreign companies is lesser-developed soft skills (The World Bank, 2013). Additionally, a low proficiency of English in Africa (Animal King, 2016) affects the employment opportunities of African micro-workers as it has a direct impact on the quality of the work delivered.

\subsection{The Microwork Process}

The process of outsourcing microtasks is represented in Figure 1.

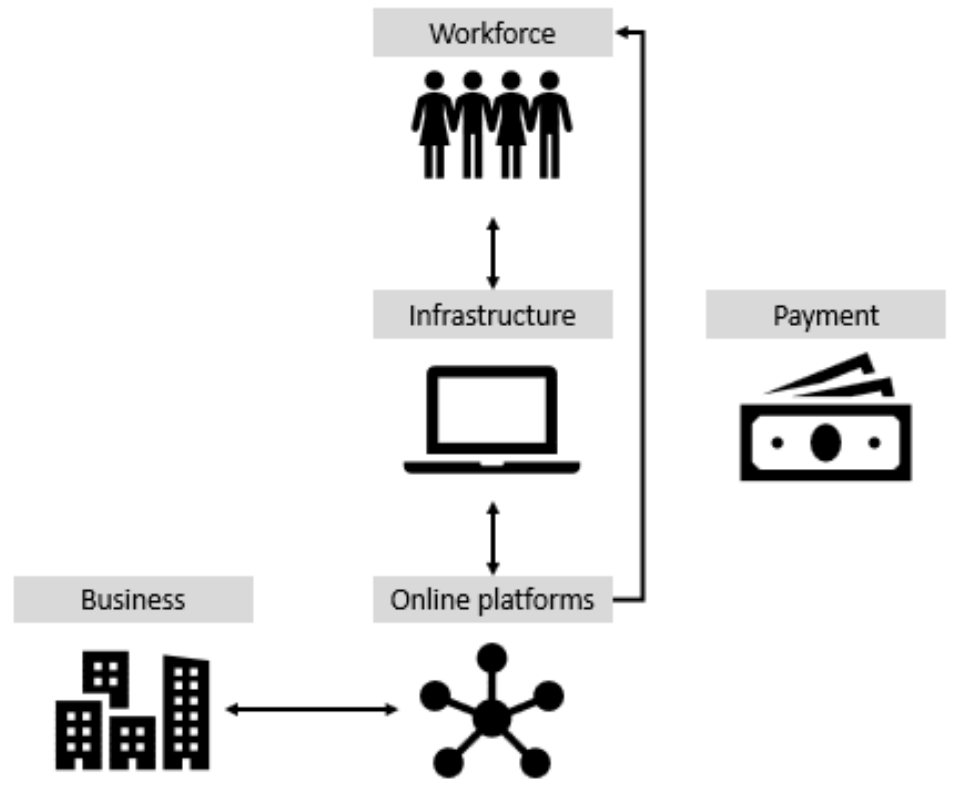

Fig. 1. Micro Work Process (Kuek et al., 2015).

\section{Companies (demand side).}

On the demand side of the process, companies increasingly demand data processing due to the digitisation of business processes, services and products, as well as a frequent collection of data by individuals and businesses (Mudanvanhu \& Van Belle, 2018). Large tasks and projects are broken up into micro-tasks and outsourced to developing countries which improves the unemployment rate in these countries, frees local human resources and delivers high-quality products at a lower price. Examples are the first online micro-working platform, Amazon Mechanical Turk, which relies on microwork to collect data and process customer information, Instagram who pays a fee for "Liking" images or writing responses and Apple, who uses micro-workers to test apps in the appstore in different countries (Kuek et al., 2015).

\section{Online platforms.}

Online platforms bring together workers and businesses in their marketplace. Supply and demand work closely with these platforms to provide microwork and for micro-workers to find tasks to be performed. The jobs are described as human intelligence tasks (hits) (Jabu Mtsweni, n.d.).

\section{Infrastructure.}


Companies require no additional resources to outsource microwork beyond an Internet connection and an account on a microwork platform. Costs are controlled by the size of the microwork task and standard rates on the platform. Companies can select micro-workers based on experience and skills for an additional fee (Amazon Mechanical Turk, n.d.).

Micro-workers require a platform account and an Internet-connected device which could be owned, borrowed or as a public connection such as at an Internet cafe (Meyers, Minic, Raftree, and Hurst, 2017)

\section{Micro-workers.}

Micro-workers are the people who perform the work from anywhere in the world via an Internet connection. Currently, the majority of micro-workers are from America followed by India and the Philippines. In Europe, micro-workers are mainly people from Serbia and Romania. The typical microworker is a millennial (born after 1980), male, with a baccalaureate degree and less than one year of experience (based on profiles from CrowdFlower).

\section{Payment.}

The typical method of payment for microwork is PayPal or currencies such as Amazon gift cards on Amazon Mechanical Turk. However, this can be an issue in developing countries and remote areas which do not have access to these payment channels (Meyers, Minic, Raftree, and Hurst, 2017; Raja, Imaizumi, Kelly, Narimatsu, \& Paradi-Guilford, 2013).

\subsection{Challenges and Potential Barriers}

Studies show that there are many barriers and prejudice the investigation of the sources both from the demand side and the supply side (Kuek et al. The global opportunity in online outsourcing, 2015).

\section{Barriers to business.}

Studies have identified six significant barriers to businesses using microwork.

Quality control: The most common barriers are about the quality of work and control of the results (Jabu Mtsweni, n.d.). For microwork to be successful requires clear definitions of the job requirements (Meyers, Minic, Raftree, and Hurst, 2017).

Quality of deliverable: The most common barriers are about the quality of work and control of the results (Jabu Mtsweni, n.d.). For microwork to be successful requires clear definitions of the outcome (Meyers, Minic, Raftree, and Hurst, 2017).

Data Security: Protection against cyber-attacks. Data security is a significant factor in outsourced microwork. While cyber attacks or phishing are ever-present dangers of the Internet, there is a higher perceived risk in developing countries which is increased through lack of security awareness skills amongst developing country workers (Meyers, Minic, Raftree, and Hurst, 2017).

Fair pay: With little to no power of negotiating prices through the phenomenon of "race to the bottom" where business keep costs down, micro-workers will take any work at any price. This puts higher skilled and lower skilled worker on a par but can disadvantage companies that requiring greater efficiency (Van Belle \& Mudavanhu, 2018). [check reasoning]

Method of payment: In developing countries where online payment systems like Google Wallet and PayPal do not exist, and many people do not have bank accounts it is difficult to perform safe and direct payments (Jabu Mtsweni, n.d.).

Working conditions: Social benefits and legislation. Since micro-workers are unregistered, they do not enjoy the social benefits such as health insurance or minimum wages which makes them susceptible to exploitation. In contrast, at least one study showed that a high percentage of online employers considered micro-workers more honest than permanent employees (Kuek et al. The global opportunity in online outsourcing, 2015)

\section{Barriers to micro-workers.}


Three issues are identified as significant barriers to micro-workers.

Infrastructure: Access and price. Internet infrastructure is a significant barrier to potential microworkers. In Africa, especially in rural areas, Internet connections are mostly by means of mobile devices due to the lack of wired infrastructure, requiring smartphones, tablets and $3 \mathrm{G}$ dongles. The cost of these connections varies widely between countries and can be prohibitive for potential microworkers. Also, many rural areas do not have a stable supply of electricity. However, provision of these infrastructures could be a solution to the problem of migration from rural areas which causes overpopulation in the cities (Can, 'Micro Work' Gives Digital Jobs to World's Poor, 2013).

Access to computers: High rates of access to mobile devices do not assure access to computers. Although telecentres are a potential solution, the considerable growth in ownership of smartphones in Africa points to them as a more likely solution to this barrier (Kuek et al. The global opportunity in online outsourcing, 2015).

Payment: Without access to bank accounts or online payment platforms payment solutions such as prepaid debit cards (Kuek et al. The global opportunity in online outsourcing, 2015) and paying in commodities (Jabu Mtsweni, n.d.) have been proposed.

\subsection{Prejudice to micro-workers in Africa}

Outsourcing microwork to Africa is negatively impacted by prejudice. Firstly, African workers are considered unskilled and lacking in proficiency in the English language resulting in companies fearing poor quality of service. Secondly, the prejudice that African micro-workers are willing to work for meager prices can result in exploitation. Thirdly, biases exist in the area of gender and socio-political constraints in the developing countries.

Prejudices extend to infrastructure, in particular, stable electricity supply and Internet connectivity. Moreover, with few confidential statistics and academic studies were done on Africa companies in the developed world, constraints exist due to lack of contact and the availability of accurate facts about Africa. Consequently, companies may be prejudiced thereby excluding large groups of potential workers from developing countries (Van Belle \& Mudavanhu, 2018).

\subsection{Current situation}

Africa has the youngest and fastest growing population and workforce in the world combined with high youth unemployment. The digital economy, including microwork, is considered by some as a potential solution to unemployment, especially with the rapid spread of Internet connectivity across the continent (Van Belle \& Mudavanhu, 2018). African governments, such as Nigeria and Kenya, are aware of microworks' potential of helping their people to work and obtain money and are actively encouraging microwork (Onkokame, Schoentgen \& Gillwald, 2018).

In Belgium, the term "outsourcing" is known as Belgium already outsources IT-related services, credit management, logistics, administration, and production. Whereas Belgium outsources mainly directly to foreign parties, online outsourcing is relatively unknown but is currently being investigated (Graydon, n.d.; KBC, n.d.; Petitjean, 2017). Although classical wage-earning labour dominates Belgium employment, the economic crisis, labour reforms and the advent of digitisation which provides access to thousands of workers make microwork outsourcing attractive to companies. However, it is unclear of the impact this can have on the Belgian labour-market. While online outsourcing may create jobs for unskilled young people from regions with high unemployment, it may result in Belgian workers losing their jobs. This concern has prompted a call for reformation of labour laws to include online outsourcing (High Council of Employment, 2016). 


\section{Research Approach}

To answer the research questions, we undertook a numerical survey amongst Flanders companies who employ a minimum of five employees, operate in the services sector and who are potential outsourcers of microwork. The approach was positivist in nature. The research is exploratory, trying to uncover attitudes and issues in a descriptive manner. No prior research model or framework was used, since we are not attempting to confirm hypotheses.

The instrument was informed by prior literature but a few pilot interviews further informed the questionnaire design. The sampling framework was based on a public directory of Flemish companies. Due to low responses, five sourcing methods were employed: telephonic, mail, events, networking and social media. The answers to the completed surveys were aggregated and are presented in the findings section.

\section{Findings and Discussion}

Of the 198 respondent companies and in contrast to expectations, the survey showed that slightly less than $30 \%(\mathrm{n}=59)$ of the respondents are aware of online outsourcing. $77 \%$ of these $(23 \%$ of total respondents, $\mathrm{n}=46$ ) were familiar with microwork even though there are no Belgian microwork platforms and a lack of advertising for microwork. Of the $23 \%$ who were aware of microwork outsourcing, $20 \%$ ( $4.5 \%$ of total respondents) had outsourced microwork while $30 \%$ of those who have not previously outsourced microwork (28.3\% of total respondents) indicated their willingness to do so when suitable.

The respondents were divided into three profiles. The first profile was the $4.5 \%$ who have already outsourced microwork. The second profile were those who indicated that they were interested in outsourcing microwork ( $28.3 \%$ of respondents) and the third profile were those for which microwork may be applicable but were not interested (31.8\% of respondents). The balance of respondents (35.4\%) for whom microwork is not applicable were not included in any profile.

\subsection{Profile 1: "We already have experience outsourcing microwork."}

Reasons for outsourcing microwork differed according to the size of the companies. Companies with 50 or fewer workers outsourced microwork for reasons of speed and low cost while companies with over 50 employees did so to increase capacity. In both cases, ease of access to micro-workers was a factor. Only one of the profile one companies did so out of anthropological reasons with the aim of assisting in reducing unemployment, providing personal development in developing countries, social responsibility, or multicultural cooperation.

Of the outsourced work, $30 \%$ was data capturing, $25 \%$ data filing, and $25 \%$ other tasks. The balance was equally spread between text transcription, company information searching and capturing, and analysing and describing images. The most widely used platform was Amazon Mechanical Turk mainly due to the reputation of Amazon and because they are the market leader in the microwork platforms. Other platforms included micro-workers, Crowdsource and Cloudfactory.

Most of the microwork was outsourced to other European countries (55.6\%), mainly the Balkan countries of Albania, Bosnia and Herzegovina, and Bulgaria. Thus, outsourced jobs remained within the European Union thereby reducing legal liabilities. In addition, 33.3\% of the companies outsourced to Asia and $11.1 \%$ to North and South America and Africa respectively.

Just less than $89 \%$ of the outsourcing companies are satisfied with the quality of the delivered tasks (Figure 1). This compares well with the satisfaction (78\%) of the speed of the response since this was the most recurring motive for outsourcing microwork. Additionally, all companies were satisfied or 
very satisfied with the relative cost of its implementation. $77 \%$ of companies are satisfied or very satisfied with the administrative process and communication between the company itself, microworking platform and the micro-workers. Only $11 \%$ were previously not satisfied with the protection of data which was due to some data loss.

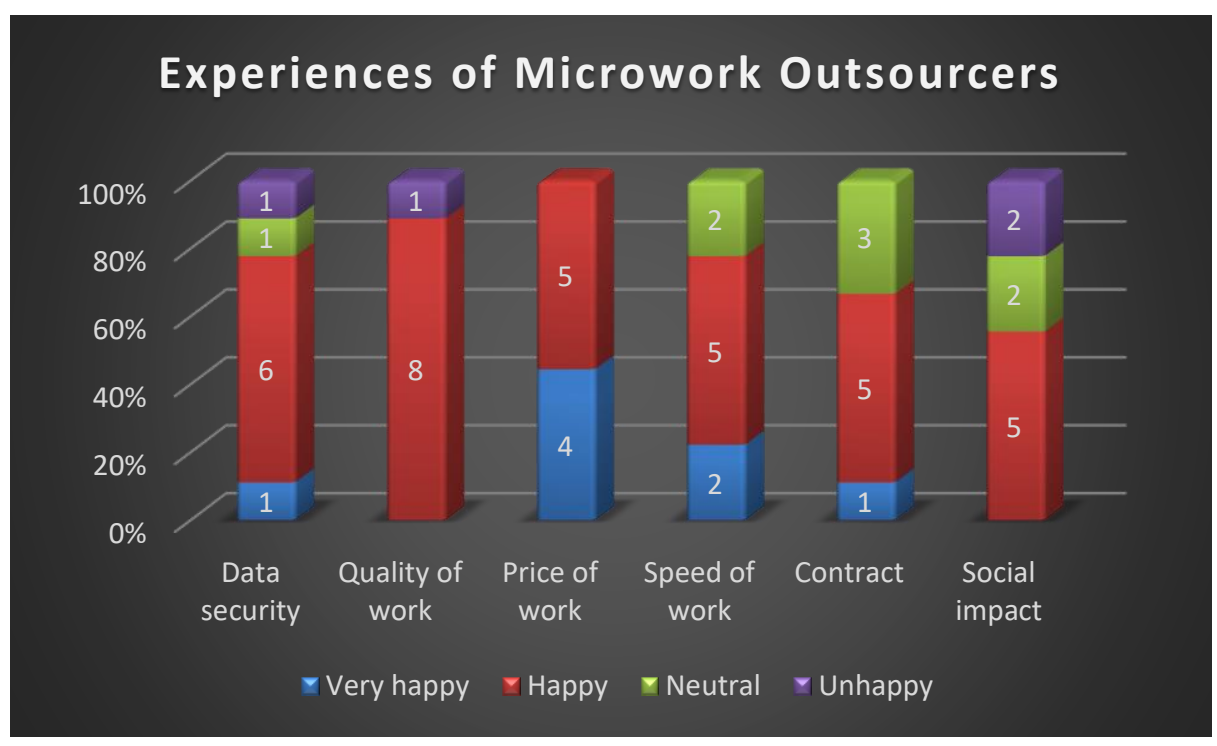

Fig. 2. Experience of the Microwork Providers $(n=9)$

Given that only one of companies gave social responsibility as a reason for outsourcing, it was interesting to note that five companies felt that outsourcing microwork created a positive social impact.

In summary, companies that have had experience with outsourcing microwork are generally satisfied with the combination of speed, quality and cost.

\subsection{Profile 2: Interested in outsourcing microwork}

This profile comprised two groups: companies willing to outsource microwork to Africa and companies willing to outsource microwork but not to Africa. Although most companies had not heard about outsourcing microwork, $71.4 \%$ of this profile were open to outsourcing microwork to Africa. $73.2 \%$ of those interested were medium or large companies ( $>50$ workers).

The most significant barriers were cyber-security $(62.5 \%)$, quality of deliverables $(43.8 \%)$ and quality control (37.5\%). Legislative barriers $(37.5 \%)$ related mostly to the introduction of new legislation and GDPR as well as the lack of clear microwork legislation in Belgium. Method of payment $(25.0 \%)$ ranked fifth, and concern for fair pay (18.8\%) last. The average ranking scores for each of these, comparing the ratings for outsourcing in general with outsourcing specifically to Africa, are shown in Fig. 3. 


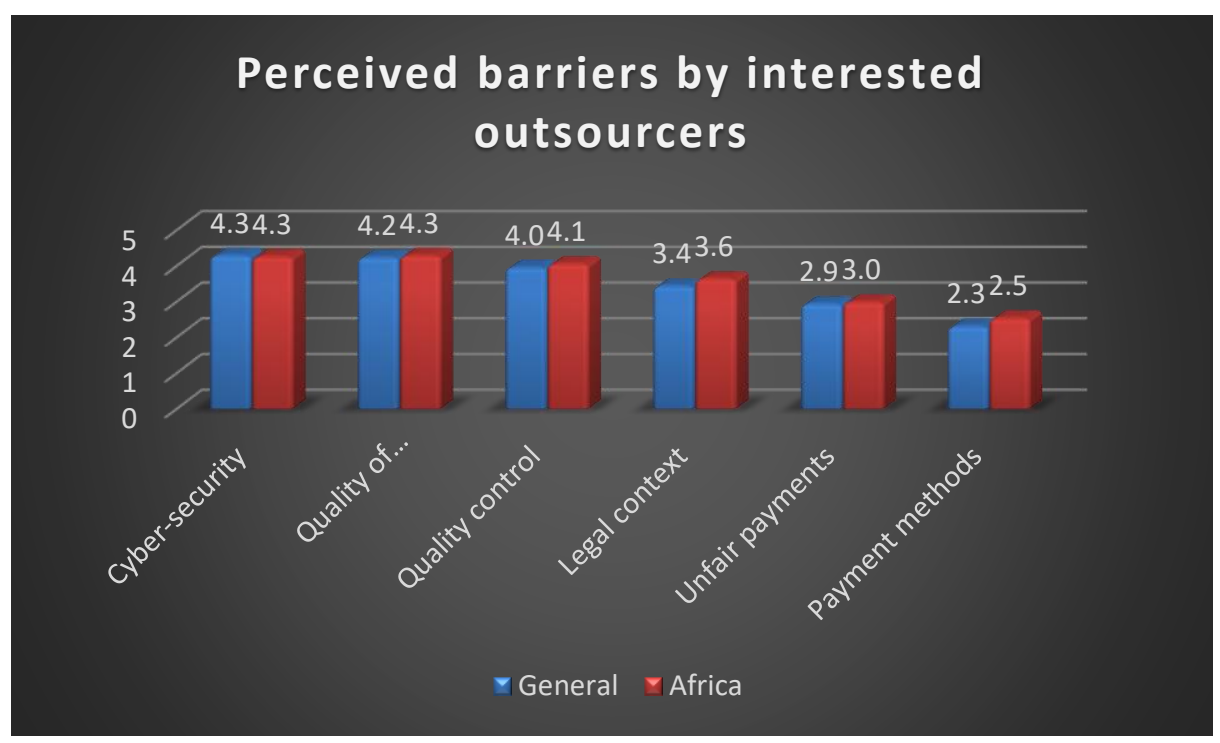

Fig. 3. Perceived barriers by companies interested in microwork outsourcing $(n=56)$

Although the barriers were not observed to differ between Africa and other countries, there was evidence of five prejudices preventing companies outsourcing microwork to Africa: $63.3 \%$ were concerned about risk of failure by the African micro-worker; $49.0 \%$ were concerned about the response times; $44.9 \%$ were concerned about the educational level of the micro-worker; $36.7 \%$ were concerned about the political instability in Africa; and 14.3\% about economic instability in Africa (Fig.4).

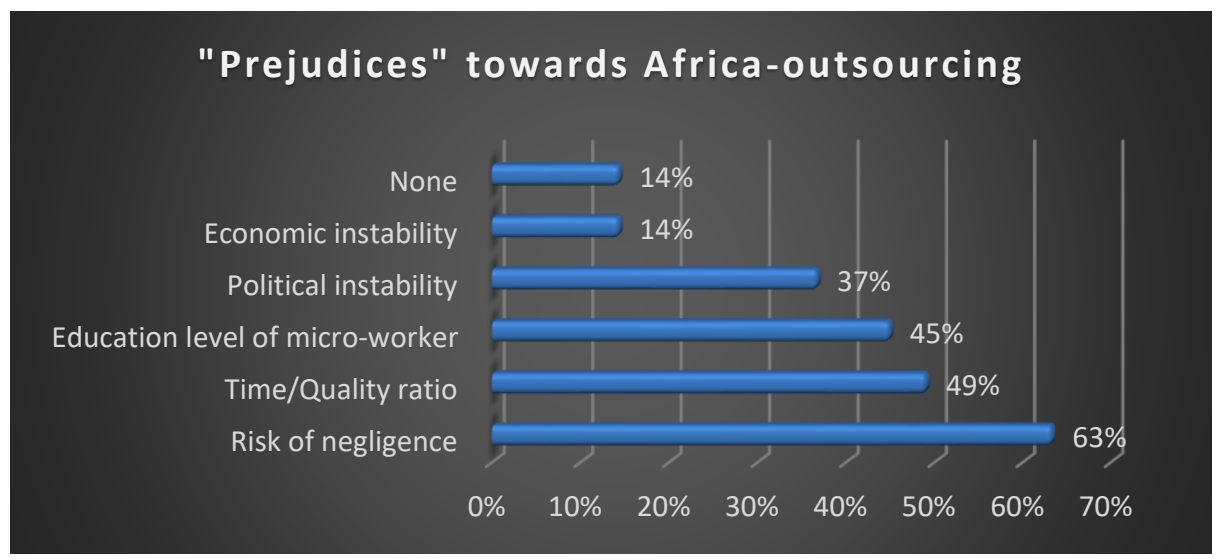

Fig. 4. Perceived issues (“prejudices") with outsourcing to Africa $(\mathrm{n}=56)$

\subsection{Profile 3: Are not interested in outsourcing microwork to Africa}

Of the total number of respondents, $31.8 \%$ reported no interest in outsourcing microwork. The primary concerns of these respondents resemble those of the profile two respondents: cyber-security; quality; and legislation. The most significant barrier to outsourcing microwork was cyber-security $(36.5 \%)$ followed by quality control $(34.9 \%)$, quality of deliverables (34.9\%), legislation $(31.7 \%)$, fair pay $(23.8 \%)$, and payment method $(0.325)$. 


\subsection{Findings summary}

Four groups of respondents were detected: those who have outsourced microwork; those who intend to; those who do not intend to; and those that have no reason to outsource microwork. Barriers to outsourcing microwork for companies intending to outsource microwork and those companies not intending to outsource were observed to be similar except for the method of payment. The exception may be due to the irrelevance of payment if the companies do not intend to use the service. The barriers were ranked in descending order of importance as cyber-security, quality of deliverable, quality control, legislation and fair pay. However, those companies that had already outsourced microwork were shown to be satisfied at an equally high level with cybersecurity, quality and administrative issues which includes payment.

\section{Recommendations}

Based on the findings, four recommendations are proposed to make microwork familiar to Flemish companies and promote outsourcing of microwork to Africa.

- Further research is needed to present a strong business case providing both costs and values for outsourcing microwork from Europe to Africa accentuating the value-add to the outsourcing company.

- Information sharing events should be organised to promote awareness of outsourcing microwork to Africa and to address the above areas of concern.

- $\quad$ Organisations such as "Entrepreneurs for Entrepreneurs" whose mission is to promote sustainable economic growth in developing countries, through the support of local entrepreneurship should become involved in the project.

- Encourage companies that are currently not interested in outsourcing microwork to pilot microwork outsourcing to Africa through collaboration with outsourcing support organisations.

Given that most African governments are currently trying to attract electronic labour-broking platforms as part of their 4IR strategy to alleviate local unemployment, it is hoped that this research presents some views from an outsourcing provider perspective and offers tangible strategies to encourage non-African organisations to outsource micro-work to Africa-based workers.

\section{References}

Amazon Mechanical Turk. (n.d.). Human intelligence through an API. Retrieved from AMT http://www.mturk.com.

Amazon Mechanical Turk. (n.d.). Pricing. Retrieved from AMT https://www.mturk.com/pricing

Boyd, C. (2014, November 18). Micro Work: Making money from mobiles. Retrieved from BBC http://www.bbc.com/future/story/20120601-money-making-mobiles

Bukht, R., \& Heeks, R. (2017). Defining, conceptualising and measuring the digital economy. Development Informatics working paper, (68).

The Flemish Government. (n.d.). NACE. Retrieved from Flemish Government https://www.vlaanderen.be/nl/ondernemen/een-eigen-zaak-starten/nace-code

European Commission. (n.d.). List of NACE codes. Retrieved from European Commission http://ec.europa.eu/competition/mergers/cases/index/nace_all.html

Global impact sourcing coalition. (n.d.). Retrieved from GISC: https:/gisc.bsr.org/ 
Graham, M., Hjorth, I., \& Lehdonvirta, V. (2017). Digital labour and development: impacts of global digital labour platforms and the gig economy on worker livelihoods. Transfer: European Review of Labour and Research, 23(2), 135-162.

Graydon. (n.d.). Debt management outsourcing. Retrieved from Graydon: https://graydon.be/incasso/debiteurenbeheer-uitbesteden

High Council of Employment. (2016, June). Digital economy and labor market. Retrieved from http://www.krispeeters.be/sites/default/files/HRW\%202016-2.pdf

Jabu Mtsweni, LB (n.d.). The potential benefits of mobile micro services work in developing nations: Research opportunities and challenges. Retrieved from www.researchgate.net: https://www.researchgate.net/publication/271417907_The_potential_benefits_of_mobile_mi crowork_services_in_developing_nations_Research_opportunities_and_challenges

Kan, D. (Director). (2013). Micro Work' Gives Digital Jobs to World's Poor [ Movie].

KBC. (n.d.). How can I outsource my administration? Retrieved from KBC: https://www.kbc.be/ondernemen/nl/artikel/administratie/boekhouding/hoeadministratieuitbesteden.html

Kuek, SC, Paradi-Guilford, C., Fayomi, T., Imaizumi, S., Ipeirotis, P., Pina, P., and Singh, M. (2015). The global opportunity in online outsourcing. The World Bank.

McManus, P. (Director). (2016). The digital human: micro work [ Movie].

Meyers, L., Minic, B., Raftree, L., \& Hurst, T. (2017). The nexus or micro work and impact sourcing: Implications for young employment.

Mtsweni, J., \& Burge, L. (2014). The potential benefits of mobile microwork services in developing nations: Research opportunities and challenges. In 2014 IST-Africa Conference Proceedings (pp. 1-10). IEEE.

Onkokame, M., Schoentgen, A., \& Gillwald, A. (2018). What is the state of microwork in Africa? A view from seven countries. Policy Paper, 5.

Petitjean, F. (2017, 3 March). Belgian outsourcing unpopular domestically. Retrieved from Computable: everything about business ICT in Belgium. Retrieved from: https://www.computable.be/artikel/nieuws/outsourcing/5969307/5440850/belgischeoutsourci ng-niet-geliefd-in-eigen-land.htm

Raja, S., Imaizumi, S., Kelly, T., Narimatsu, J., \& Paradi-Guilford, C. (2013). Connecting to work. The World Bank.

Rockefeller Foundation. (n.d.). Digital jobs in Africa. Retrieved from Rockefeller foundation: https://www.rockefellerfoundation.org/our-work/initiatives/digital-jobs-africa/

Roomaney, Z., Van Belle, J. P., \& Tsibolane, P. (2018). Mobile Micro-work in South Africa. The Americas Conference on Information Systems (AMCIS2018), 6, 2018.

Van Belle, J.P., \& Mudavanhu, S. (2018). Digital labor in Africa: A Status Report. Global development institute, SEED.

World Bank. (2013, February). Feasibility study: micro work for Palestinian territories. Retrieved from www.un.org/unispal/: https://unispal.un.org/pdfs/WBank_MicroworkPalTerritories.pdf 